\title{
The Management Consultancy for Promoting Exotic Destinations for Health Tourism
}

\author{
Assoc. Prof. Dr. Mariana Ianeva ${ }^{1}$, Dr. Stiliyana Basmadzhieva ${ }^{2}$ \\ Department "Economics of Tourism”, University of World and National Economy, Sofia, Bulgaria
}

\begin{abstract}
:
The relevance of the topic is determined by the need to promote tourism destinations which are providing exotic experiences in a healthy environment. In this regard, exotic destinations for health tourism are the focus of management consultants who develop projects aimed at travel agencies in order to research, analyze and promote such products. The object of research are exotic health destinations, the subject is their promotion through consulting projects. The aim is to bring out the opportunities for highlighting and promoting exotic recreational products that will return tourists to health tourism destinations after the implementation of a consulting project. The results are aimed at travel agencies and health tourism destinations, which in times of crisis need to restructure their product offerings focused on current consumer needs.
\end{abstract}

Key words: management consultancy, tourism destinations, health tourism, promotion

\section{Introduction}

The relevance of the topic is determined by the need to promote tourism destinations providing exotic experiences in a healthy environment. In this regard, exotic health tourism destinations are the focus of management consultants which develop projects aimed at travel agencies in order to research, analyze and promote such products. The object of research are healthy exotic destinations, the subject is their popularization through consulting projects. The aim is to point out the opportunities for highlighting and promoting exotic recreation products to return tourists in health tourism destinations after the implementation of a consulting project. The results are aimed at travel agencies and health tourism destinations, which in times of crisis need to restructure their product offerings focused on current consumer needs. The methodological framework is based on systematic and holistic approaches and it covers: analysis and synthesis; induction and deduction; analogy; abstraction; comparative analysis; statistical and descriptive methods. 


\section{Research}

\subsection{The management consultancy for promoting tourism destinations.}

Management consulting is a dynamic and fast-growing sector, which in order to meet the needs of the clients must maintain and develop economic and social competencies aimed at different sectors of the economy. The activity of consulting has become increasingly relevant in the American and European markets over the past fifty years, due to the rapid development of services in various sectors, digitalization, new forms of social communication, increasing competition and the desire of managers to ensure more stable market positions and cover a larger segment of it. Often in times of crisis, consulting companies have the resources to develop projects imposed in a specific market environment.

In 2019 the value of the management consulting market worldwide is 160 billion dollars, with statistical data showing growth every year from 2011 to 2019 (Statista Research Department, 2020).

The most important development determining the dynamics of the market is the creation of e-business and e-commerce. It can be assumed that e-commerce is not a new sector, but rather a new dimension of business and consulting. The development of econsultancy is associated with a number of paradoxes. It is characterized by many innovations, dynamics and investments until the period of 2000. The boom in econsultancy is very short, although the Internet is creating many new opportunities for the development of consultancy (Lewis, 2006).

The Internet has developed extremely fast in the recent years, causing a radical change in the search for tourism travel information. For this reason we are witnessing a large number of web-based marketing campaigns and successful Internet solutions in the field of tourism. It has been established that Internet environment allows successful realization on the market of tourism entities (hotels, tour operators, agencies, etc.). In essence, multimedia appearance on the Internet leads to high financial results in real ecommerce on corporate Internet sites (www.travelocity.com, www.orbitz.com, www.expedia.com. www.booking.com, etc.).

The promotion on the Internet of various travel products by consulting companies has a good return for various countries and travel agencies around the world. According to a recent study by J. Clement from April 2020, the number of Internet users already exceeds 4.5 billion people, representing about $59 \%$ of the world's population. The active users of social media, in turn, are 3.81 billion people. At the end of 2018, Asia is the region with the largest number of online users - just over 2 billion. Europe ranks second with almost 705 million internet users (Clement, 2002).

The thesis proves the important role of the consulting for a travel agency, which in times of crisis strives to maintain its business by offering tourism products for attractive destinations, even in non-specific market conditions.

The role of the consulting company is to offer a plan in the form of a consulting project of the travel agency. By using it to target more solvent customers who appreciate it and have the opportunity to meet their needs of leisure and experiences by 
traveling to attractive destinations. It also advises its customers to prepare special promotional offers for larger groups by renting charter flights to specific destinations, in order to offer the product at more competitive prices, as well as minimizing factors such as policies of companies on scheduled airlines in conditions of crises.

In the tourism industry, PR is focused on travel, tourism destinations, hotels and restaurants. Each area has a specific target audience and it is necessary to apply different tools for sending different target messages. (Water, 2016)

The consulting company must determine the profile of the services and the prospective clients - selected travel agencies with experience in packaging similar types of products. To prepare a plan for establishing on the market and to accomplish marketing research of the existing competitors.

The activity of the consulting company at the travel agency is expressed in:

- development of project ideas;

- preparation of financial statements for the project;

- project management;

- organization of seminars, preparatory courses and trainings;

- organization of conferences, symposiums, round tables and all public relations forms to promote travel to attractive destinations;

- publishing activity - scientific publications, tourism sites, magazines, tourism brochures, catalogs, advertising materials and others;

- proposals and preparation for participation in tourism fairs or online tourism exhibitions of a new type.

Consulting projects aimed at travel agencies have certain specifics related to the product preferences of their potential customers, which in a health crisis select and choose from destinations that are imposed as healthy locations, often from the exotic group. In this regard, it is necessary to analyze the specifics of travel agencies and the possibilities for consultants to offer them an up-to-date project for the specific time range.

\subsection{Tour operator package tour}

The traditional role of the travel agent is to serve as a "travel expert". Travel agents are a major source of travel information for tourists traveling individually or in a group. They are professionals who have accumulated a significant amount of knowledge and advices and their recommendations are essential for tourists. Agents are expected to know the services of various travel companies as well as the geography of the world. Therefore, a number of experts predict that in the future the provision of information and consulting will become a leading activity of the travel agencies.

The information-consulting activity of the travel agent working in a team with a consulting company aims to present in the best possible way the application of the contractors (suppliers) by type, quality, price characteristics, discounts. Depending on the specific preferences and wishes of the clients, as well as according to their financial capabilities, the travel agent can direct the clients' choice to the most suitable travel tour or individual travel services. 
The researches of the supply by the consulting companies is aimed at selecting a suitable destination, providing a safe and healthy environment, tourism policy providing protection and prevention of tourists, selection of vehicles, accommodation, attractions and contractors - service providers at the destination. The attention in these studies is focused on the components of the tourism product in a selected destination.

A similar integrated model adapted by management consultants is the below, created by Christopher Cooper (Cooper, 2008).

Fig. 1.TOURISM SYSTEM - INTEGRATED MODEL

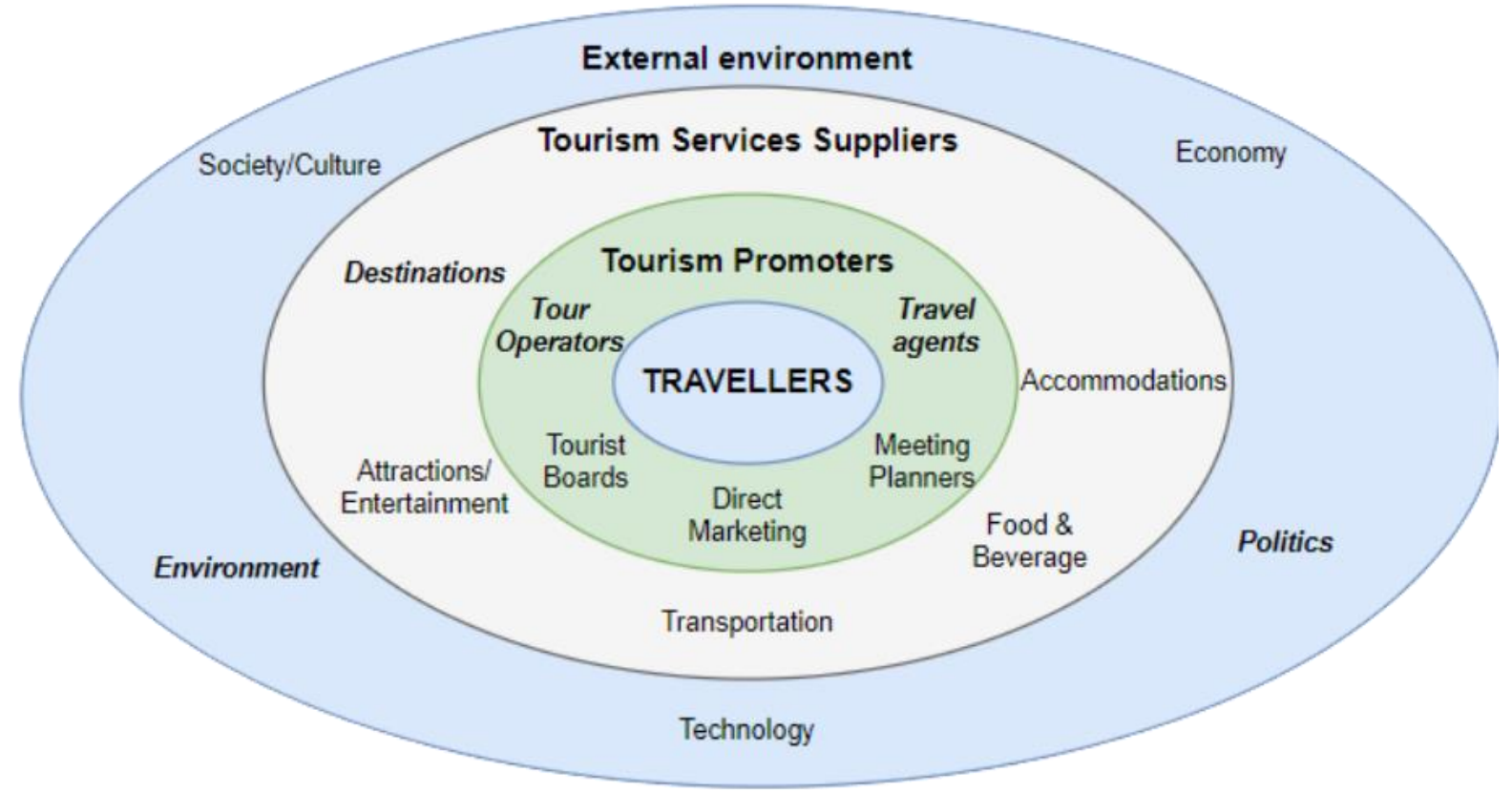

Source: Author's adaptation by Cooper, Ch. et al., Tourism: Principles and practice - Fourth edition, Prentice Hall, Pearson Education Hall, England, 2008

In the case of a developed consulting project, one of the first phases of its implementation is related to the planning of programs for new destinations, the tour operator may take part in a sightseeing tour sponsored by the marketing organization of the respective destination, carriers or service providers, or at his own expense. Sightseeing tours allow the tour operator to assess the potential of the program, of the ground services and to assure partnership for its promotion.

The comparison of the results of the supply surveys with those of the demand surveys allows to compile the final working project of the tourist trip, which is set in the project offer. In the presence of a working project, the tour operator is directed to specific contractors. The presence of tour operators and travel agencies in the Internet environment drastically changes both the promotion and distribution of the tourism product. The webpages of most tour operators and travel agencies give consumers the 
opportunity to either buy a holiday package or plan every detail of their vacation through an interactive electronic travel agency. The client can first choose the desired destination, and then make a reservation in a particular hotel, buy a plane ticket and even a sightseeing program. Potential tourists are provided with complete information about the destination, as well as about the possible ways of payment - by credit card now or later by check or cash. The websites of the Bulgarian travel agencies represent a timid attempt for interactive communication with the users and their quality is not at the required level.

As can be seen from the already mentioned examples, e-commerce on the tourism market occupies an increasing share of the total volume of sales of tourism tours and the opportunities that arise in the tourism industry, as a result of e-commerce, are huge. These possibilities are explored and implemented in the project of the consultants for the travel agency, in order to create and offer a new tourism product. Of course, the current destinations need to be positioned and offered professionally by the consulting company and the travel agency in order to reach the end user.

\subsection{Promotion of exotic destinations of health tourism}

For the nature and specifics of health tourism to be clarified, we should first discuss the theoretical concepts concerning tourism as an industry, whose features, taking into account the diverse needs and requirements of tourists, determines the need to offer and differentiate specialized forms of tourism, contributing to the restoration not only of the vital forces of the individual and his recreation, but also in order to improve his health - mental, physical and emotional.

According to Smith, M. and Puczko, L. (2014) health tourism is a specialized type of tourism in which ordinary tourist activities are associated with an active pursuit of improving human health. The scientific literature abounds with terms that meet this definition, including medical, balneo and spa tourism. All of them correspond to the traditional concept of health tourism, based on the use of natural healing resources for the treatment of patients (tourists) in a resort setting. The terms "restorative" or "curative" tourism, including fitness and wellness, are an echo of the relatively new trends in health tourism. The main idea of this innovative trend is the improvement of the physical condition of the client (tourist) and his health, which is not necessarily related to the application of natural healing resources, summarize Tsonev, N. and Basmadzhieva, S. (2017)

The policy of the legislative and executive power related to the proper exploitation of the natural resources used for the purposes of health tourism, as well as the regulations concerning the rights to use them, are of major importance for the development of health tourism. Last but not least, the created specialized superstructure has an impact, which in combination with the previously listed factors should help to increase the effect of the application of health tourism products related to improving the quality of life, prevention, rehabilitation, diagnosis and treatment. Marketing management in this direction should aim to achieve similar results for both national tourists and incoming international tourists. (Ayuningtyas \& Fachry, 2020)

As can be seen from the analyzes of Dudensing, Hughes and Shields (2011), the promotion of the tourism product in selected destinations is influenced by all the listed 
factors concerning the research, preparation and realization of the product by the consulting company and the tour operator. The promotion of the respective destination chosen by the tour operator and the tourism package prepared by them have a number of characteristics. They are related to the anthropogenic and natural resourses of the destination, the attractions and entertainment in it, the competitive characteristics of the selected products from suppliers - hoteliers and transporters and many additional benefits - emotional nuances of the service, high quality and dreams become true for the client, who will select the respective product. (Ianeva and co, 2015)

The creation of a differentiated image of the destination has become an important element for the formation of a competitive and distinctive image of the tourism place. In today's dynamic global market, there is an intense competition between different destinations. In some places, it is much more intense, depending on a number of criteria, due to common outgoing markets, similar products and experiences, similar target market segments, approximately the same distance from key markets, similar economic growth and the same peak tourist seasons. This leads to the conclusion that the image of the destination is one of the main factors for choosing the place for their next trip by tourists, as it influences their behavior.

Destination marketing organizations, tourism consulting firms and other interested institutions also monitor changes through their research and contacts. When they are ask for help by travel agencies with limited or relatively limited experience with international partners, they start creating projects that assist the agencies in developing mainly new destinations that they have not worked with so far. This saves them money on personal research, as well as benefit from the rich experience of consultants on previous identical projects. The main task of the marketing organization of the destination (MOD) is to promote a city, region or country in order to increase the number of visitors. It encourages the development and supply of a destination by focusing on conventional sales as well as marketing of tourism and services (Yaneva, 2019).

In times of crisis, it is very easy to lose or gain market share, so the main priority of travel agencies is to maintain their market position. They must allocate serious funds for the promotion and advertising of the tourism product. The object of research and supply in times of crisis are the so-called attractive destinations, often implemented through charter programs. They are identified in the client's mind as dreamed, desired and long-planned. Usually these are more distant and sunny places for recreation and entertainment for a target group, mainly related to outbound tourism.

In general, exotic tours are offered to a limited target group of potential tourists. Very often the lack of suitable offers and their unprofessional promotion lead to a decrease or lack of interest in conducting such tours. At the same time, they are a good market niche for some tour operators, as standard tours on the market are not always of interest.

According to the authors, the travel agency must maintain a constant attractive image by targeting different consumer segments. Very useful would be the so-called testimonial techniques for promotion and advertising - sharing the experiences of individuals with a product or service. This approach involves targeting tourism advertising first to leading markets that are opinion leaders and make political and 
business decisions, because they will also affect smaller markets. Advertising is necessary, but pure PR is the best option for promoting tourism. The information value of the Internet is becoming increasingly important for the launch of the tourism product, and the comments that are shared are an important source for improving the services.

\subsection{Empirical research in the development of Consulting Project for promoting exotic health toursim destinations}

The consulting company - an object of the study in the present paper, directs its projects to travel agencies with solvent clients, to which it offers programs in healthy exotic destinations.

Marketing research by a consulting company is a key approach to obtaining up-todate information. The global crisis is affecting tourism and there is a serious decline in the industry. Unlike the mass tourist, who has limited financial resources, the targeted market segment, interested in exotic destinations, is characterized by other features. The focus is on customers with good financial opportunities, willing to spend a significant amount to ensure a safe destination that will contribute to improving the health status of the individual, as well as luxury, comfort, recreation, high quality service and an exciting experience in non-traditional atmosphere. For this type of tourists it is important to content their most demanding requirements in order to maximize travel satisfaction and win them as loyal customers. They seek not only for physical recreation during their stay in a health tourism destination, but also for conditions for emotional restart, experiences and ensuring mental harmony.

Another important aspect in the formation of the competitive product in the development of a competitive project is a study of the activities of established travel companies offering exotic travel to health tourism destinations.

Based on a study of the leaders in this field, we can distinguish "Profi Tours" Ltd., "Royal Travel", "Profi Travel Center", "Luxury Travel", "Infinity Travel" and other travel agencies. The variety of proposals for exotic destinations raises the question of what is the necessary condition for the development of a profitable product. When developing the project by the consulting company, the emphasis is on offering high quality service to tourists by the staff at the tourist offices. In order to promote the offered product, it is necessary to conduct a powerful advertising campaign to attract potential customers. In the conditions of health and economic crisis, the possibility for a flexible pricing policy with regard to the offered product is also essential.

The object of study are five travel agencies operating on the market by offering exotic destinations.

The next stage in the development of the consulting project is the selection of specific destinations to be offered in the exotic tours. Initially, the attention of the travel agency is planned to be focused on several destinations, with the prospect of increasing their number due to the acquired experience and skills for the profitable development of this type of activity.

The choice of destination is determined by its safety for the health of the tourists and the presence of specific natural and anthropogenic resources that they can offer to the potential tourists. Other factors, also important for the choice are accessibility to the tourism destination, accommodtion conditions in it, institutional factors, price for the 
consumer, readiness to receive tourists. (Ianeva, 2020) Based on these criteria, consultants focus on offering Maldives, Thailand, Cuba and Mexico.

After determining the specific destinations, the accommodation places and the services of the different transport companies are selected. The elements of the infrastructure and the service are also important, which facilitate the use of the tourism attractions in the respective territory. All these elements must be taken into account when planning the use of territorial units for tourism purposes.

The consulting agency advises its clients - travel agencies - to offer lower package prices for the good hotels. In addition, a contract for organizing a charter program with an overnights stay in these destinations could be signed, which significantly reduces the cost, as well as provides an opportunity for safe return of the tourists in the case of termination of the flights, because of force majeure.

In these unprecedented times, comfortable travel opportunities are more important than ever. The charter service provides exceptional flexibility for companies and organizations that want to transport groups of up to 239 passengers, combined with the calmness to be able to choose the service, route and schedule that best suits their needs. The charter service offers a convenient and personalized solution for every large group. (Travel News, 2020)

With the selection of the package components and the clarifications with the client, the consulting company finishes with the project of the program and continues with contracting and its promotion.

Developing a model for the promotion of attractive destinations is aimed at influencing potential consumers. The consultants recommend advertising the programs for exotic destinations through informational brochures and tourism catalogs (online or paper), improving the agency's website, as well as participating in tourism expo with options for an online participation in the scope of today's specific tourism environment. Public relations, through all its tools, is also extremely valuable.

In the concept of exotic destinations for health tourism, we are no longer talking only about their specific components, but also including the requirements for healthy living, imposed by the specifics of the current crisis. The promotion of these tours is performed through the well-known forms of PR, and on top of them the consultants add new ones in the project proposal:

- overall public relations of the travel agency;

- specialized tourism catalogs and brochures;

- participation of the agency in tourism fairs and expos, as well as online ones;

- improving the Internet communication and the application of the Internet marketing in the management and distribution of the travel agency.

The process of consulting for promoting the destination is organized in the form of a project, which includes:

$\checkmark$ Marketing research;

$\checkmark$ Customer research;

$\checkmark$ Defining the specific product;

$\checkmark$ Promotion of the specific product on the market through tourism expos, catalogs and the best types of Internet advertising. 
In the formation and promotion of the specific tourism product in the consulting management project, it is necessary to offer all tools, techniques and forms for the promotion of the product of the travel agency, which has sought consulting intervention.

\section{Conclusion}

Based on the introduction, are proved the possibilities of the consulting activity for the promotion of tours to exotic destinations for health tourism.

Based on the above, it is proved the authors's position on the importance of the consulting activity for supporting the business of travel agencies. It is proved the statement that in times of crisis, maintaining market position of the outgoing travel agencies is extremely important and could be supported through the intervention of an external consultant and a properly developed consulting project.

The attractiveness of a specific destination for tourists is determined by cultural and psychological dimensions, which is why the promotion of a specific destination uses certain symbols related to health, safety, exoticism, traditions, climate and others. These symbols are placed in brochures and catalogs, as well as in Internet advertising.

Taking into account the specific tourism consumption in the current crisis, it is necessary that the promotion of this type of destination should include information on the requirements for a healthy stay, and this needs to be emphasized in the project developed by the consultants.

\section{References}

1. Clement, J., Global digital population as of April 2020, Available: https://www.statista.com/statistics/617136/digital-population-worldwide/ (Visited on 20.04.2020)

2. Cooper, Ch. et al., Tourism: Principles and practice - Fourth edition, Prentice Hall, Pearson Education Hall, England, 2008

3. Dumilah Ayuningtyas, Anwar Fachry, Ni Nyoman Dwi Sutrisnawati, Sayyidatul Munawaroh, Medical tourism as the improvement of public health service: A case study in Bali and West Nusa Tenggara, Enfermería Clínica, Volume 30, Supplement 6, 2020, Pages 127-129

4. Dumilah Ayuningtyas, Anwar Fachry, Ni Nyoman Dwi Sutrisnawati, Sayyidatul Munawaroh, Medical tourism as the improvement of public health service: A case study in Bali and West Nusa Tenggara, Enfermería Clínica, Volume 30, Supplement 6, 2020, Pages 127-129

5. Harold Lewis, Choosing and Using Consultants \& Advisers , March 2006, Publisher: Kogan Page Ltd

6. Ianeva, M. and co, Tourism destinations, House "Publishing complex-UNWE", Sofia, 2015, http://blogs.unwe.bg/myaneva/files/2018/03/Book-TourismDestination-Mariana-Ianeva.pdf 
7. Ianeva, M., Developing a Methodology for Tourism Region Management (The Case of Sofia), Economic Studies, 2020, Vol. 29 Issue 6, p171-181. 11p., ISSN 0255-0822 (Scopus) https://www.iki.bas.bg/spisanie-ikonomicheski-izsledvaniia (секция „Архив“, година 2020, бр. Available: https://www.scopus.com/sourceid/13500154704?origin=recordpage

8. Rebekka M. Dudensing, David W. Hughes, Martin Shields, Perceptions of tourism promotion and business challenges: A survey-based comparison of tourism businesses and promotion organizations, Tourism Management, Volume 32, Issue 6, 2011

9. Smith, M., Puczko, L., Health, Tourism and Hospitality - Wellness, SPAs and medical travel, Second Edition, Routledge, New York, 2014.

10. Statista Research Department, Size of the global management consulting market from 2011 to 2020, Available: https://www.statista.com/statistics/466460/globalmanagement-consulting-market-size-by-sector/ (Visited on 09.04.2020)

11. Travel News, December 2020, Available: https://travelnews.bg/bg/news/16070817796701/-wizz-air-veche-shte-pravi-ichartarni-poleti-?fbclid=IwAR3Ai958XkbI5CfBk_P2tnC7UuiiKHk_qneJxG_RFMeX2LCfF4lbicL-Bg

12. Tsonev, N., Basmadzhieva, S., "Opportunities for development of medical tourism in Bulgaria", Sixth International Scientific Conference for Students and $\mathrm{PhD}$ Students "Infrastructure: Business and Communications", UNWE, Sofia, 2017.

13. White Water PR, Role of Public Relations in travel and tourism industry, 2016, Available: https://whitewaterpruae.wordpress.com/2016/02/23/role-of-publicrelations-in-travel-and-tourism-industry/ (видяно на 15.03.2020)

14. Yaneva, M., Establishing business identification of regions for sustainability in tourism, Journal of Balkan Ecology, 2019, p. 81-87, Available: https://www.cabdirect.org/cabdirect/abstract/20193161197 